\title{
Methodological development for the optimisation of electricity cost in cement factories: the use of artificial intelligence in process variables
}

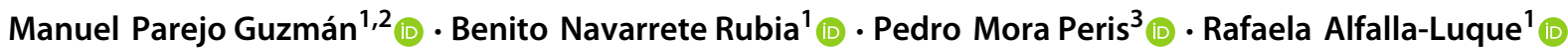

Received: 31 December 2020 / Accepted: 25 September 2021 / Published online: 10 November 2021

(c) The Author(s) 2021

\begin{abstract}
Cement factories require large amounts of energy. $70 \%$ of the variable cost goes to energy-33\% to kiln thermal energy and $37 \%$ to electrical energy. This paper represents the second stage of a broader research study which aims at optimising electricity cost in a cement factory by means of using artificial intelligence. After an analysis of the different tools that could be highly useful for the optimisation of electricity cost, for which a systematic review of the literature and surveys and an expert panel of 42 professionals in the cement sector were carried out, a methodology was developed in order to reduce electricity cost by optimising not only different variables of the production process, but also regulated electricity costs and electricity market costs. Artificial neural networks and genetic algorithms will be the tools to be used in this methodology, which can be applied to any cement plant in the world, and, by extension, to any electro-intensive consumer. The innovation of this research work is based on the use of a methodology that not only combines two different variables at the same time-process variables and regulated prices—but also makes use of artificial intelligence tools techniques.
\end{abstract}

Keywords Cement $\cdot$ Electricity cost $\cdot$ Optimisation $\cdot$ Artificial intelligence $\cdot$ Artificial neural networks and genetic algorithms

\section{Introduction: problem identification}

Cement manufacturing process consists of finely grinding a series of minerals (limestone, marl and clay) and heating them at about $1450^{\circ} \mathrm{C}$ in a cement kiln to obtain an intermediate product called clinker. The clinker is blended with gypsum (a cement setting regulator) and other additives and then ground again into a fine powder to form cement. The process consists of 9 stages which are shown in Fig. 1.

The Spanish cement sector faced a very severe crisis which brought about a drastic reduction in consumption. From 2006 up to 2014 cement consumption decreased from 55.9 million t. to 10.8 million $\mathrm{t}$, which represented a decrease of $80.67 \%$. Spanish cement companies were forced to change their strategy and started then exporting large quantities of cement and clinker to different countries in the world.

The loss of competitiveness of cement companies in recent years has led to a drastic reduction in Spanish exports. Dur-

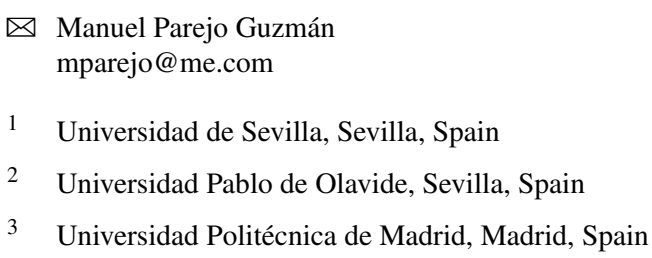

ing 2018, Spanish plants exported a total of $8,103,947 \mathrm{t}$. of cement and clinker. This amount was reduced to 6,232,043 t. in 2019-a reduction of $23.1 \%$. [26].

The energy consumption of a cement plant has a very important weight in the income statement. Energy comprises up to $70 \%$ of variable cost in a cement factory: $33 \%$ for thermal energy (Kiln) and 37\% for electrical energy [17]. Therefore, the cost of electricity consumption in cement production is a fundamental competitive factor.

Electricity costs in Spanish electro-intensive industry, according to Eurostat data, can be sometimes up to $30 \%$ higher than they are in other European countries [11]. Energy price in Spain is higher than that in most direct competitor countries. Based on a consumption between 20,000 MWh and $150,000 \mathrm{MWh}$, which is the range within which $100 \%$ of Spanish cement companies were located in 2018-excluding taxes and levies - comparative data for the cost of electricity in electro-intensive industry in the $28 \mathrm{EU}$ countries reveal that Spanish industry has one of the highest electricity costs, being only surpassed by Ireland, Malta and the UK.

While the EU-28 average electricity price for nonhousehold consumers with a consumption between 20.000 and $150.000 \mathrm{MWh}$ was $61,3 € / \mathrm{MWh}$ in 2018 , it reached $78,8 € / \mathrm{MWh}$ in Spain. 


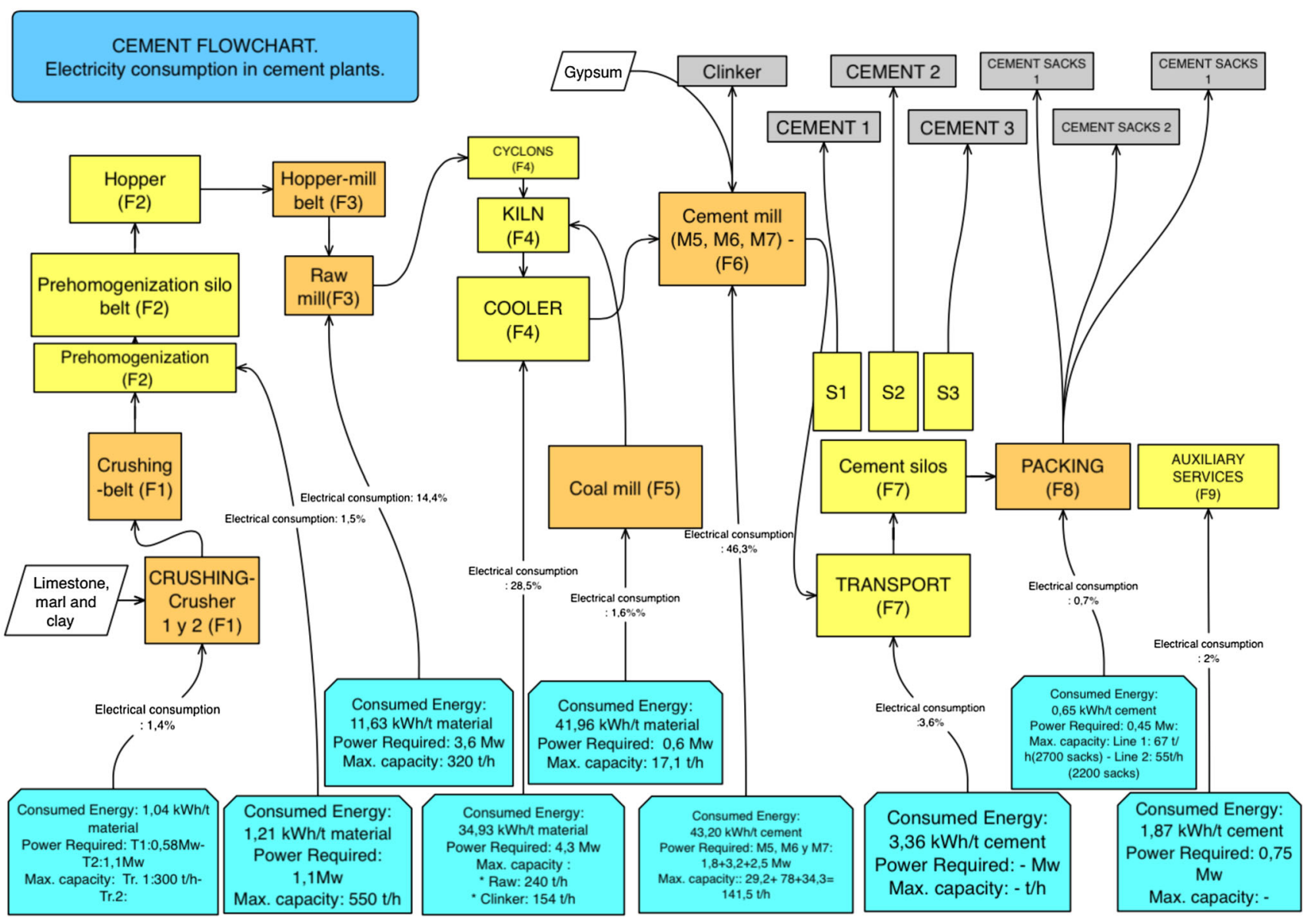

Fig. 1 Cement manufacturing process (\% of electricity consumption referred to tons of cement)

Hence, it is essential to investigate how to optimise the cost of electricity in cement factories in order to make them more competitive.

\section{Objective of the paper}

The problem of the loss of competitiveness of cement industry due to its high electricity costs is a common issue in multiple countries. In the last few months (Spring/Summer 2021), the matter has acquired great relevance in countries such as Spain. Specifically, our research pursues the development of a methodology to optimise the cost of electricity in a cement plant by means of influencing internal variables of the plant: process variables and regulated electricity cost.

By reducing costs, the plant may become more competitive. The methodology developed is perfectly valid for any cement factory in the world. In addition, it is worth mentioning that by modifying the initial parameters of the model, it could be applied to other electro-intensive industries, such as extractive mining - copper and other mineral production, automotive industry, aeronautical industry and agroindustry.
To apply it in other countries, it would only be necessary to analyse the regulated electricity costs to be taken into account, as well as the different factors that affect price formation in the electricity markets.

Using artificial intelligence (AI) for the optimisation of the cost of electricity in cement plants is the objective of a broader research study within which this article is framed. Our research study also includes a methodology aimed at reducing the cost of electricity by applying $\mathrm{AI}$ techniques to optimise the purchase of electricity [27].

\section{Methodology}

The tools that prove to be useful when applying AI to minimise electricity cost in the cement sector match those that could potentially be applied in other industrial sectors. They are mainly the following:

1. Internet of things (IoT): set of devices, objects and computers connected to the internet and communicated with each other, which help to collect information. 
2. Data mining: it is used to extract information contained in historical or real time received data, to assist in decision making [7, 31].

3. Machine learning: it is a branch of AI based on the design of algorithms, which allow machines and computers to learn from data without the need for constant human intervention. Its strong point is that the learning process is automated and improved as it consumes more data without requiring human intervention $[6,33]$.

Although in the present paper these tools are tackled, we will delve into machine learning techniques in particular in order to apply them in the model proposed.

\subsection{Main machine learning algorithms and techniques}

There are machine learning techniques and algorithms which are extremely useful for solving the kind of problem we face in our research: the optimisation of the cost of electricity in an industrial plant. These include decision tree algorithms, support vector machines, Bayesian networks, fuzzy logic, nearest neighbours, K-means, artificial neural networks (ANN) and genetic algorithms. Attention will be focussed on the last two, since they are the most recommended ones considering the systematic study of the literature and the expert panel.

\subsubsection{Artificial neural networks (ANN)}

They are mathematical models which are based on the biological behaviour of brain neurons [8, 29, 30]. They are connected in a specific way. They are organised into layers and their goal is to learn by automatically tuning themselves, so that they can accomplish complex tasks that could not be performed by classical programming.

Figure 2 shows the graphical representation of an artificial neuron. The sum of the inputs multiplied by their associated weights determines the nerve impulse that the neuron receives. This value is processed inside the neuron by an activation function that returns the new value which will be sent as the output value of the neuron.

Mimicking human brain, ANN receive a series of input values, each of which reaches a node called neuron. The first step, which is crucial for the application of the model, is the proper selection of the input data. It is essential that they be relevant data, that is, that they really affect the final result that we try to predict [15].

Neurons in the network are grouped into layers. There are three types of layers [15]:

- Input layer. It is the one that gets the information from the outside world.
- Hidden layers. They process the information internally.

- Output layer. It is the one that gets the response from the network and transfers it to the outside world.

Each of the neurons in the network has a weight, a numerical value $(\omega)$, which modifies the received input. The new values obtained leave the neurons and continue on their way through the network. The value obtained in each neuron would be a linear regression model to which a bias-_ "b"would be added: $Y=X_{1} * \omega_{1}+X_{2} * \omega_{2}+X_{3} * \omega_{3}+b$. It is not unusual that the results obtained by the neural network $(Y)$ initially do not coincide with the real result. It is due to the fact that the network should receive some training and learn how to perform its function correctly. Therefore, such training is carried out by modifying the weights of the neurons so that they get as close as possible to the desired results. Thus, one of the most widespread networks, which is known as multilayer perceptron-MLP [19], arises.

In this model, training data are entered in the network. If the result obtained with the initial weights was erroneous, weights should be adjusted until the output error is minimised or eliminated. This training algorithmic method that will be used in our research is called backpropagation. By means of derivatives, errors will be calculated by the network as the variation between the result obtained and the expected correct result for each group of weights. The goal of the backpropagation algorithm will be to minimise the error $(E)$ as much as possible. The error will be expressed as the difference between the output value and the expected correct result, and it will be squared, since it is not relevant that the error has a positive or negative value. It will also be multiplied by $1 / 2$ to simplify the square when calculating the derivative. The derivative will provide the error variation with respect to weights variation.

$E=1 / 2(y-S)^{2} \rightarrow \partial E / \partial \omega$

$E$ : Error.

$y$ : Correct value.

$S$ : Neural network output.

Once the end of the neural network is reached with a null or near-zero error, the network is considered to be sufficiently trained (Fig. 3).

\subsubsection{Genetic algorithms}

It is a method to generate the optimum solution to an optimisation problem. It starts with an initial population of individuals with a certain genetic coding. Population evolves so that only the best chromosomes will be selected to be part of the new population. To do this, mechanisms for the selec- 
Fig. 2 Artificial neuron. Source: own elaboration
Fig. 3 How does backpropagation in artificial neural networks work? Own elaboration
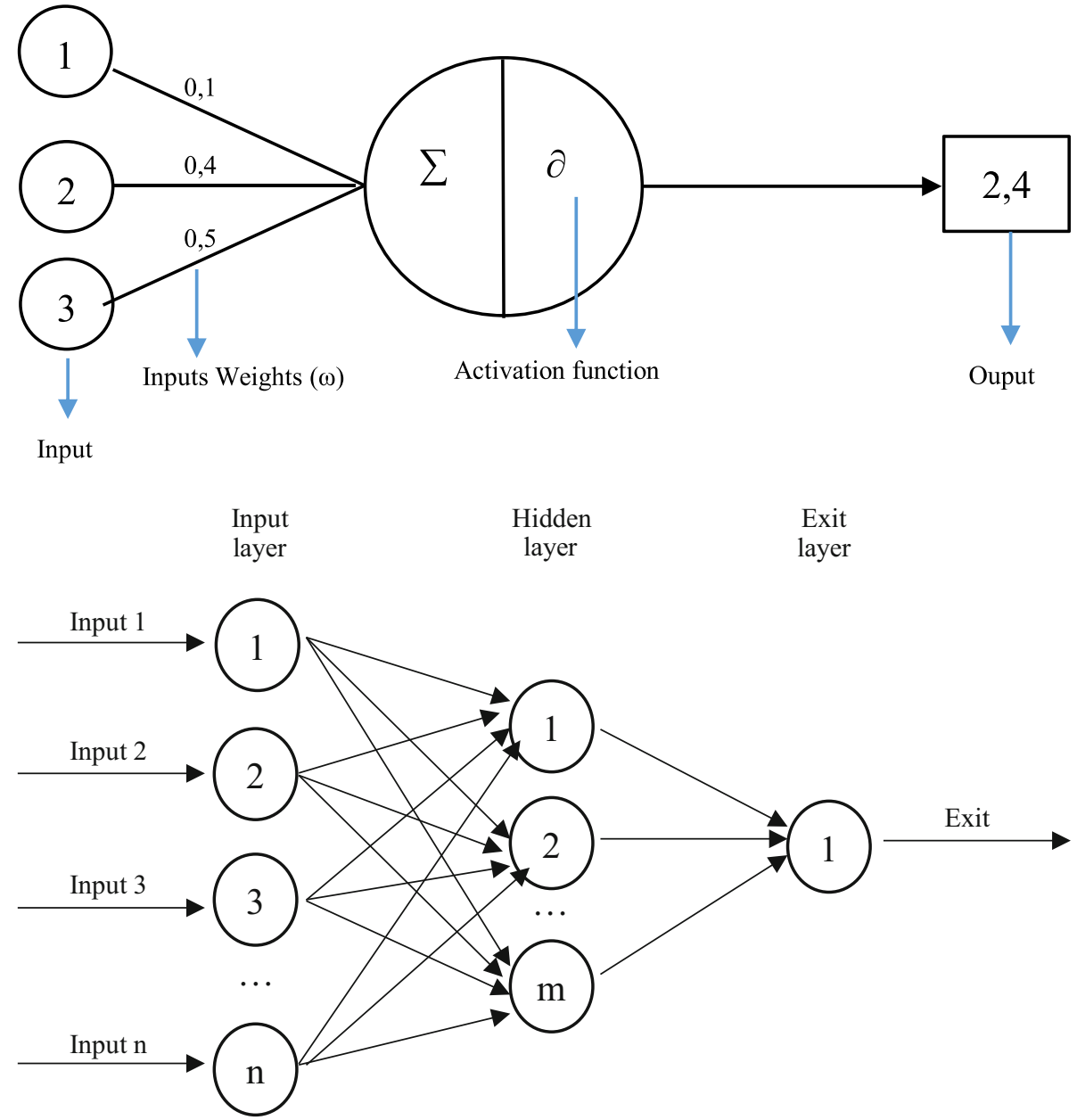

tion, crossover and mutation of chromosomes are applied until a certain stopping criterion is met. An example of a stopping criterion could be a certain number of generations or cycles, until a specific convergence criterion is reached [22]. This method can be used in combination with other algorithms such as ANN and support vector machines, with the aim of increasing performance and providing the model with a more robust solution [20, 22-24].

\subsection{Selecting specific tools to solve the problem}

The model introduced in this article was developed using the most appropriate tools to solve the problem raised and with the aim of reducing electricity cost in cement factories. Our approach followed the steps below.

\subsubsection{A systematic literature review}

In scientific literature, there are two types of literature reviews [10]: the traditional or narrative review and the systematic review of literature [21, 22]. In a systematic review of literature, achieved findings can be replicated [14]. The systematic review is defined as a process of "systematic, transparent and reproducible synthesis of research, with the dual objective of improving the knowledge base and the formulation and practice of policies" [38]. Due to its structured approach, the systematic review of literature has been widely accepted in a variety of scientific fields, such as social sciences, education and supply chain management $[1,12,25,34]$.

The field of study of our research is focussed on the optimisation of electricity cost in cement companies by using AI. Therefore, a search was conducted by introducing keywords (electricity, optimisation, cement, artificial intelligence, industry and energy). The sources of information selected were Scopus, Web of Science and ABI Inform Collection databases. The search period run until May 2021.

After an initial selection of the articles related to the subject that were found in the databases, a total of 12 articles were selected $[2-4,9,16,17,28,35-37,39,40]$. The study of the previous literature provided quite a reduced number of articles dealing with the issue of our research and which contained very limited information. Only four of those articles considered the cement sector $[9,35-37]$. The rest of them were either intersectoral articles $[3,16,17,28,39,40]$ 
or general-industry oriented articles [2, 4]. After a detailed analysis of them, the following conclusions were reached:

(a) Although all the articles dealt with issues related to the one that is object of our analysis, only four of them [9, 35-37] were specifically focussed on the cement sector and on the aspects addressed in this paper. Particularly,

+ Article [9] approached the process of optimising thermal energy consumption in La Robla cement factory in Tudela Veguín, Spain, by means of using statistical tools (AI was not applied). The initial planning, along with several initial methodological aspects of this study, served as a reference for our study.

+ Article [37] approached a simulation model conducted in four cement plants in South Africa, which enabled as much as $7.1 \%$ energy savings (electricity savings and thermal energy savings). To reach those savings, a managing methodology, which considered the crude mill, the kiln, the coal mill, crushers, cement mills and other auxiliary machinery, was carried out. Hence, a model was developed to distribute the load among the different days of the week and seasons of the year and always searching for the off-peak energy times. Although it also addressed thermal energy cost, the analysis of this methodology was extremely useful for the present research when shifting electricity consumption to the most economical off-peak periods.

+ Article [36] approached the problem of the cement market in South Africa, where a remarkable increase in electricity costs took place, which brought about an important pressure on international producers. An energy management system (EMS) was implemented in order to cut the electricity bill. This system, apart from controlling the periods of highest consumption, shifted electricity demand to the most economical daily off-peak times.

+ Article [35] focussed on managing and controlling thermal energy. Some of the factors detailed in this article were quite useful for our research, although they did not refer to electricity consumption.

(b) Six of the articles [4, 16, 17, 28, 39, 40] focussed on the study of different questions related to the optimisation of electricity purchase in the markets. Although those questions were of interest for our research as a whole, they did not tackle specific aspects that are addressed in this paper.

(c) Although two of the articles [2, 3] provided a generic reference to AI and/or to industry in general, they did not address in depth any of the aspects analysed in the present research. Therefore, they were used for general matters.

In addition to these articles, a doctoral thesis was analysed [13]. It studied thermal energy savings in a clinker kiln, as well as electricity savings in cement grinding by introducing certain modifications to different variables.

Due to the scarce contributions of the previous existing literature, the consultations with experts that are detailed in the following session were considered to be fundamental and extremely interesting. They complemented the information obtained from the literature and specified it with information collected from highly specialised sources in order to develop a proposal which was adapted to real and current needs of the sector.

\subsubsection{Surveys and expert panel}

Following the systematic review of literature, a study based on surveys and an expert panel was conducted thanks to the involvement of a total of 42 managers.

The expert panel has proved to be an effective method for improving the development of a research study, as well as for providing additional information on its quality [5, 18]. Surveys and the expert panel provided us with relevant information to design the methodology that will enable us to optimise the cost of electricity by using AI.

Quinlan et al. [32] state that when bringing together a group of experts it is fundamental not only to count on experts in the specific field under evaluation, but also on reviewers with an interdisciplinary experience. The experts that were chosen for our research met this requirement. In all cases, they were professionals with between 22 and 41 years of experience in different posts in the sector. Economists, civil engineers, industrial engineers, mine engineers and chemists, among others, were consulted.

In addition, it may be stated that all cement companies that operate in Spain were considered when selecting the group of experts. The involvement of the experts brought great added value to our research thanks to their high experience and knowledge of the sector.

Surveys, mainly used to obtain quantitative data, were conducted among a total of 11 managers. This information was extremely useful for arriving at another of the results of our research. A quite utterly novel quantitative study about the composition of regulated electricity cost in Spanish cement industry was carried out. It was of great use for the optimisation of regulated electricity costs in our research.

A total of 31 experts participated in the expert panel, and they provided qualitative data on electricity prices behaviour, operational costs of production machinery, the process variables that affect electricity consumption, flexibility in start/stop conditions of production machinery and 
on operational routines. Five of the thirty-one experts that collaborated with qualitative data, those who were considered to be experts in AI, were asked to fill in a questionnaire in order to evaluate the adequate tools to be used for the development of our model.

For qualitative data collection from the panel of experts, two questionnaires and a phone survey were carried out:

(1) A questionnaire to analyse regulated costs along with the major or minor influence of the different process variables. The variables that were selected by the experts were the ones that applied in the ANN architecture, which is represented schematically in Fig. 4.

(2) A questionnaire to evaluate the most adequate tools to solve the problem raised in this article. As it has already been mentioned, five of the experts were specialists in AI. The use of ANN along with the backpropagation and genetic algorithms turned out to be the techniques selected by $80 \%$ of the experts consulted, which happened to be in line with the majorly used tools in the articles of the previous literature studied. [16, 17, 27, 38, 39].

(3) Finally, to avoid group answers conditioning, phone surveys were carried out with each of the experts consulted. They aimed at deepening the answers that were given in the questionnaires.

Thanks to all the information gathered through the systematic review of literature, surveys and the expert panel in the cement sector, the most suitable AI tools for the optimisation of electricity consumption were selected and the model to be applied was developed.

\subsection{Development of the working methodology: application of specific tools}

The information used to assess electricity consumption was provided by Malaga cement factory (Spain), which belongs to FYM HeidelbergCement Group. The case of this factory is completely analogous to the rest of cement plants. Therefore, the results obtained will apply to any cement manufacturing plant.

The development of the methodology for the fulfilment of our objective has two different levels:

\subsubsection{A methodology for operational electricity optimisation}

The purpose is to reduce electricity consumption in a cement factory by modifying certain variables of the production process. To do this, power consumption and the variables on which it depends will be analysed in detail at each of the stages of the process [37].
There are 5 stages in the cement manufacturing process which are critical to electricity consumption (crushing, raw material grinding, clinker manufacturing, coal grinding and cement grinding). For each of those stages, the variables that affect electricity consumption and which could be easily influenced to optimise electricity consumption-without incurring large costs or investments-were identified. Then, 5 consumption functions were obtained, one for each stage, for which we will use the following nomenclature:

- $\mathrm{CE}_{(t i)}$ : electricity consumption/crusher electricity power $(\mathrm{kW})$.

- $\mathrm{CE}_{(\mathrm{M})}$ : electricity consumption/the raw mill electricity power $(\mathrm{kW})$.

- $\mathrm{CE}_{(\mathrm{H})}$ : electricity consumption/kiln electricity power $(\mathrm{kW})$.

- $\mathrm{CE}_{(\mathrm{MC})}$ : electricity consumption/coal mill electricity power $(\mathrm{kW})$.

- $\mathrm{CE}_{(\mathrm{MCEM})}$ : electricity consumption/cement mill electricity power $(\mathrm{kW})$.

- $\mathrm{CE}(F x)$ : stage $X$ net electricity consumption (kWh).

- $\mathrm{V}(n)_{F X}$ : " $n$ " variable with impact on electricity consumption in stage $X$, being $n=1,2, \ldots, X=1,3,4,5$ y 6 .

- $\omega_{n X}$ : variable " $n$ " weight in stage $X$.

- $u$ : the value obtained in each of the neurons in the network will be a linear regression model to which a bias $(u)$ should be added.

The selection of the variables that impact on electricity consumption, which was made for each stage of the cement manufacturing process, will be described below.

1. Raw materials extraction /crushing (Stage 1: $F 1$ ). The two variables that can influence electricity consumption and which were included in the data collection process are:

- Size of crusher 1 output product (primary crusher): $V(1)_{F 1(t 1)}$

- Size of crusher 2 output product (secondary crusher): $V(2)_{F 1(t 2)}$

For each data pair (a-b, c-d, etc.), we will get an energy consumption result $(X, Z, Y, \ldots)$ (Table 1$)$. The objective will be to minimise that energy consumption, that is, to determine the pair of $V(1)_{F 1(t 1)}$ and $V(2)_{F 1(t 1)}$ values which reduce $F 1$ energy consumption to a minimum.

Electricity consumption will be calculated according to the following expressions:

$$
\begin{aligned}
& \mathrm{CE}(F 1)_{(t 1)}=\mathrm{CE}_{(t 1)} F\left[V(1)_{F 1(t 1)}, * \omega 11\right. \\
& \left.+V(2)_{F 1(t 1)} * \omega 21+u_{1}\right] * H_{(t 1)}
\end{aligned}
$$


Fig. 4 Artificial neural network operation with backpropagation algorithm. Source. Own elaboration

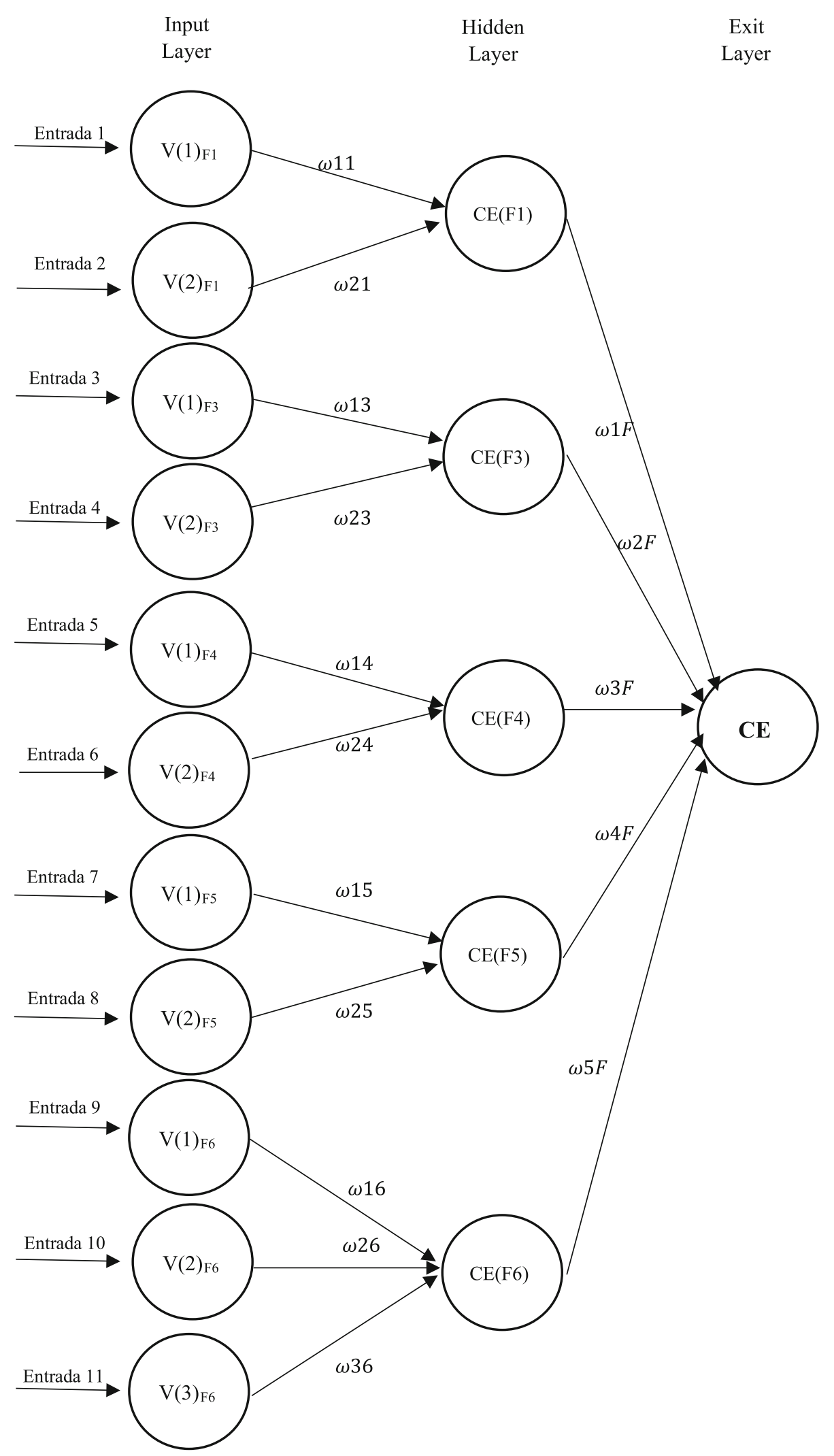


Table 1 Energy consumption result for each data pair (own elaboration)

\begin{tabular}{lll}
\hline$V(1)_{F 1(t 1)}$ & $V(2)_{F 1(t 1)}$ & $\mathrm{CE}(F 1)_{(t 1)}$ \\
\hline $\mathrm{a}$ & $\mathrm{b}$ & $\mathrm{X}$ \\
$\mathrm{c}$ & $\mathrm{d}$ & $\mathrm{Z}$ \\
$\mathrm{e}$ & $\mathrm{f}$ & $\mathrm{Y}$ \\
\hline
\end{tabular}

$\mathrm{CE}_{(t 1)}$ : Primary crusher electricity consumption.

$\mathrm{H}_{(t 1)}$ : Primary crusher operating hours.

$u_{1}$ : Bias.

Each of the two variables - $V(1)$ and $V(2)$ - will affect the net energy consumption at this first stage $\left(\mathrm{CE}(F 1)_{(t 1)}\right)$ with a weight that will be represented" by " $\omega$ ".

For the secondary crusher, the consumption function would be similar:

$$
\begin{aligned}
\mathrm{CE}(F 1)_{(t 2)}= & \mathrm{CE}_{(t 2)} F\left[V(1)_{F 1(t 2)} * \omega 11\right. \\
& \left.+V(2)_{F 1(t 2)} * \omega 21+u_{1}\right] * H_{(t 2)}
\end{aligned}
$$

$\mathrm{CE}_{(t 2)}$ : Secondary crusher electricity consumption.

$H_{(t 2)}$ : Secondary crusher operating hours.

$u_{2}$ : Bias.

The function that would integrate the two crushers would be:

$$
\begin{aligned}
\mathrm{CE}(F 1)_{(t 1, t 2)}= & \mathrm{CE}_{(t 1)} F\left[V(1)_{F 1(t 1)} * \omega 11\right. \\
& \left.+V(2)_{F 1(t 1)} * \omega 21+u_{1}\right] * H_{(t 1)} \\
& +\mathrm{CE}_{(t 2)} F\left[V(1)_{F 1(t 2)} \omega 11\right. \\
& \left.+V(2)_{F 1(t 2)} \omega 21+u_{1}\right] * H_{(t 2)}
\end{aligned}
$$

2. Raw mill (Stage 3: F3).

Since it is a ball mill, the four variables which most influence electricity consumption at this stage are:

- Input raw material size: $V(1)_{F 3}$.

- Mill rotational speed: $V(2)_{F 3}$.

- Mill filling level: $V(3)_{F 3}$.

- Balls diameter: $V(4)_{F 3}$.

Acting in the same way we did in the previous stage, we would get:

$$
\begin{aligned}
\mathrm{CE}(F 3)= & \mathrm{CE}_{(\mathrm{M})} F\left[V(1)_{F 3} * \omega 13+V(2)_{F 3} * \omega 23+u_{3}\right. \\
& \left.+V(3)_{F 3} * \omega 33+V(4)_{F 3} * \omega 43+u_{3}\right] * H_{(\mathrm{M})}
\end{aligned}
$$

$\mathrm{CE}_{(\mathrm{M})}$ : Raw mill power consumption.

$H_{(\mathrm{M})}$ : Raw mill operating hours.

$u_{3}$ : Bias.
3. Clinker manufacturing (Stage 4: F4).

The two variables that were identified as the ones that most influence electricity consumption at this stage are:

- False air entering cyclones: $V(1)_{F 4}$

- Clinker granulometry: $V(2)_{F 4}$

Operating in the same way we did in the previous stage, we would get:

$$
\begin{aligned}
\mathrm{CE}(F 4)=\mathrm{CE}_{(\mathrm{H})} F\left[V(1)_{F 4},\right. & \\
& \left.* \omega 14+V(2)_{F 4} * \omega 24+u_{4}\right] * H_{(\mathrm{H})}
\end{aligned}
$$

$\mathrm{CE}_{(\mathrm{H})}$ : Kiln electricity consumption.

$H_{(\mathrm{H})}$ : Kiln operating hours.

$u_{4}$ : Bias.

4. Coal grinding (Stage 5: F5).

The following two variables were selected as the ones that may most influence electricity consumption at this stage:

- Carbon size/granulometry: $V(1)_{F 5}$.

- Mill rotational speed: $V(2)_{F 5}$.

Operating in the same way we did in the previous stage, we would get:

$$
\begin{aligned}
\mathrm{CE}(F 5)=\mathrm{CE}_{(\mathrm{MC})} F[ & V(1)_{F 5}, \\
& \left.* \omega 15+V(2)_{F 5} * \omega 25+u_{5}\right] * H_{(\mathrm{MC})}
\end{aligned}
$$

$\mathrm{CE}_{(\mathrm{MC})}$ : Coal mill electricity consumption.

$H_{(\mathrm{H})}$ : coal mill operating hours.

$u_{5}$ : Bias.

5. Cement mill (Stage 6: F6).

In FYM Heidelberg Cement Group Malaga Factory, there are 3 cement mills: 5, 6 and 7 .

A collection of data related to the four variables which can influence electricity consumption at this stage was carried out:

- Clinker size: $V(1)_{F 6(M 5, M 6, M 7) \text {. }}$

- Plaster size: $V(2)_{F 6(M 5, M 6, M 7)}$.

- Other additions size: $V(3)_{F 6(M 5, M 6, M 7) \text {. }}$

- Mill rotational speed: $V(4)_{F 6(M 5, M 6, M 7)}$.

Operating in the same way we did in the previous stage, we would get (Table 2).

$$
\begin{aligned}
\mathrm{CE}(F 6)=\mathrm{CE}_{(\mathrm{MCEM})} & F\left[V(1)_{F 6},\right. \\
& * \omega 16+V(2)_{F 6} * \omega 26+u_{6}+V(3)_{F 6}, \\
& \left.* \omega 36+V(4)_{F 6} * \omega 46+u_{6}\right] * H_{(\mathrm{MCEM})}
\end{aligned}
$$


$\mathrm{CE}_{(\mathrm{MCEM})}$ : Cement mill electricity consumption.

$H_{(\mathrm{H})}$ : Cement mill operating hours.

$u_{6}$ : bias.

The aim will be to minimise electricity consumption at these 5 stages taking into consideration the above-mentioned 14 variables, so that if changes are required in the installation or the operational process in order to minimise electricity consumption, these neither imply a significant expense nor a high investment. It is simply a matter of finding the optimal combination of variables $V(n) F_{x}$ which minimise electricity consumption in the factory.

To optimise the 14 variables- $V(n) F_{x}$-we will use the artificial neuronal network structure with the backpropagation algorithm that is shown in Fig. 4. It is in effect recommended by the analysed literature and experts contacted as the most effective tool. The 14 variables are present in the input layer. Each of them will affect electricity consumption at a different " $i$ " stage $\left(\mathrm{CE} F_{i}\right)$. Such stages are included in the second layer of the neural network. Each variable will affect the consumption of the stage with a different weight. The weights are represented as $\omega_{i j}$.

$i$ : Number of the variable.

$j$ : Stage it affects.

In addition, the following will be made come true for each stage:

$$
\begin{aligned}
\omega_{11}+\omega_{21}= & 1 / / \omega_{13}+\omega_{23}=1 / / \omega_{14}+\omega_{24}=1 / / \\
& \omega_{15}+\omega_{25}=1 / / \omega_{16}+\omega_{26}+\omega_{36}=1 .
\end{aligned}
$$

The neural network will need to be trained. To do this, different combinations of actual values of the 14 variables- $V(n)_{F i}$ - which will be taken from the information collected in the historical database of the plant, will be introduced into the model. For each combination of variables, the factory will get a CE value of the real electricity consumption observed $(y)$. The neural network will perform a series of calculations with random weights $\left(\omega_{i j}\right)$ for each variable, and different output values $(s)$ will be obtained. The goal of the neural network will be to minimise the error $(E)$ between the value actually obtained in the factory $(y)$ and the output value obtained with the neural network $(s)$.

$E=\frac{1}{2}(E)^{2}$

The error will be minimised by trying to make the differences between " $y "$ and $" s "$ as small as possible (hence, by minimising partial derivatives of electricity consumption depending on the weight). To simplify the result of the derivative, the error will be squared and multiplied by $1 / 2$. Squaring will eliminate the sign of the error, since it is not relevant for our aim whether it be positive or negative. Once the error is considered acceptable, we will be able to understand that the artificial neural network is sufficiently trained and that it offers acceptable values for $\omega_{i j}$.

After the neural network is trained, the next step will be to introduce different combinations of variables $V(n)_{F i}$ into it so that it calculates the predicted electricity consumption$\mathrm{s}-\mathrm{CE}$ - by using the weights that were regarded as valid. The ultimate goal of training our artificial neural network is to reduce electricity consumption to a minimum. In order for the model to have acceptable reliability, we will give each of the 14 variables different values.

The model will provide us with the combination of values of the variables that reduces electricity consumption to a minimum. The structure of the neural network with the backpropagation algorithm would be as follows.

\subsubsection{A methodology for the optimisation of regulated electricity prices}

It is possible to improve electricity efficiency cost in a cement factory by shifting electricity consumption to the most economical off-peak periods [35].

In Spain, high voltage tariffs (with a contracted power exceeding $450 \mathrm{~kW}$ in one of the periods, that is $6 \mathrm{X}$ access tariffs) offer 6 periods of time (P1, ., P6) which range from the highest to the lowest cost. This tariff has different energy rates depending on the period of time in which it is consumed, so that the bill will reflect the energy consumed in each of the periods and the corresponding rate for each period, with $P 1$ being the most expensive period and $\mathrm{P} 6$ the cheapest one. Periods are distributed through the year according to the following table (Fig. 5).

The objective will be to optimise the cost of energy by focussing on the $€ / \mathrm{kWh}$, that is always taking the different periods $(P 1, P 2, \ldots, P 6)$ into consideration in order to use the cheapest possible $\mathrm{kWh}$.

In this section, possible decreases in contracted power will also be determined, when possible, in order to reduce fixed cost in the electricity bill. In both cases genetic algorithms will be used.

The steps to be followed in this methodological development are as follows:

Step (B1): The electricity consumption function for each stage of the cement manufacturing process ( 9 functions) will be determined for each of the 6 periods $(P 1, \ldots, P 6)$. The cement manufacturing process can be seen in Fig. 1. We will use the following nomenclature:

- $\mathrm{CE}(F X)$. Total electricity consumption in stage $X$. It will be measured in $\mathrm{kWh}$. 
Table 2 Energy consumption result for each data pair (own elaboration)

\begin{tabular}{|c|c|c|c|c|}
\hline $\mathrm{V}(1)_{\mathrm{F} 6(\mathrm{M} 5, \mathrm{M} 6, \mathrm{M} 7)}$ & $\mathrm{V}(2)_{\mathrm{F} 6}(\mathrm{M} 5, \mathrm{M} 6, \mathrm{M} 7)$ & $\mathrm{V}(3)_{\mathrm{F} 6(\mathrm{M} 5, \mathrm{M} 6, \mathrm{M} 7)}$ & $\mathrm{V}(4)_{\mathrm{F} 6(\mathrm{M} 5, \mathrm{M} 6, \mathrm{M} 7)}$ & $\mathrm{CE}(\mathrm{F} 6)_{(\mathrm{M} 5, \mathrm{M} 6, \mathrm{M} 7)}$ \\
\hline a & B & $\mathrm{c}$ & $\mathrm{d}$ & $\mathrm{X}$ \\
\hline $\mathrm{e}$ & $\mathrm{F}$ & $\mathrm{g}$ & $\mathrm{h}$ & $\mathrm{Z}$ \\
\hline $\mathrm{i}$ & $\mathrm{J}$ & $\mathrm{k}$ & 1 & $\mathrm{Y}$ \\
\hline
\end{tabular}

\section{Energy calendars in Iberian}

Peninsula

\section{1.-A taiff in working days}

\begin{tabular}{|c|c|c|c|c|c|c|c|c|c|c|c|c|c|c|c|c|c|c|c|c|c|c|c|c|}
\hline HOURS & $0-1$ & $1-2$ & $2-3$ & 3-4 & 4-5 & $5-6$ & $6-7$ & $7-8$ & 8-9 & $9-10$ & $10-11$ & 11-12 & $12-13$ & $13-14$ & $14-5$ & $15-16$ & $16-17$ & $17-18$ & $18-19$ & $19-20$ & $20-21$ & 21-22 & $22-23$ & 23-24 \\
\hline January & P6 & P6 & P6 & P6 & P6 & P6 & P6 & P6 & P2 & $\mathrm{P} 2$ & P1 & P1 & P1 & P2 & P2 & P2 & $\mathrm{P} 2$ & P2 & P1 & P1 & P1 & $\mathrm{P} 2$ & P2 & P2 \\
\hline February & P6 & P6 & P6 & P6 & P6 & P6 & P6 & P6 & P2 & P2 & P1 & P1 & P1 & P2 & P2 & P2 & P2 & P2 & P1 & P1 & P1 & $\mathrm{P} 2$ & P2 & P2 \\
\hline March & P6 & P6 & P6 & P6 & P6 & P6 & P6 & P6 & P4 & P4 & P4 & P4 & P4 & P4 & P4 & P4 & P3 & P3 & P3 & P3 & P3 & P3 & P4 & P4 \\
\hline April & P6 & P6 & P6 & P6 & P6 & P6 & P6 & P6 & P5 & P5 & P5 & P5 & P5 & P5 & P5 & P5 & P5 & P5 & P5 & P5 & P5 & P5 & P5 & P5 \\
\hline May & P6 & P6 & P6 & P6 & P6 & P6 & P6 & P6 & P5 & P5 & P5 & P5 & P5 & P5 & P5 & P5 & P5 & P5 & P5 & P5 & P5 & P5 & P5 & P5 \\
\hline 1-15 June & P6 & P6 & P6 & P6 & P6 & P6 & P6 & P6 & P4 & P3 & P3 & P3 & P3 & P3 & P3 & P4 & P4 & P4 & P4 & P4 & P4 & P4 & P4 & P4 \\
\hline $16-30$ June & P6 & P6 & P6 & P6 & P6 & P6 & P6 & P6 & P2 & $\mathrm{P} 2$ & P2 & P1 & P1 & P1 & P1 & P1 & P1 & P1 & P1 & P2 & P2 & P2 & P2 & P2 \\
\hline July & P6 & P6 & P6 & P6 & P6 & P6 & P6 & P6 & P2 & $\mathrm{P} 2$ & P2 & $\mathrm{P} 1$ & $\mathrm{P} 1$ & P1 & P1 & $\mathrm{P} 1$ & P1 & $\mathrm{P} 1$ & P1 & P2 & P2 & P2 & $\mathrm{P} 2$ & P2 \\
\hline August & P6 & P6 & P6 & P6 & P6 & P6 & P6 & P6 & P6 & P6 & P6 & P6 & P6 & P6 & P6 & P6 & P6 & P6 & P6 & P6 & P6 & P6 & P6 & P6 \\
\hline September & P6 & P6 & P6 & P6 & P6 & P6 & P6 & P6 & P4 & P3 & P3 & P3 & P3 & P3 & P3 & P4 & P4 & P4 & P4 & P4 & P4 & P4 & P4 & P4 \\
\hline October & P6 & P6 & P6 & P6 & P6 & P6 & P6 & P6 & P5 & P5 & P5 & P5 & P5 & P5 & P5 & P5 & P5 & P5 & P5 & P5 & P5 & P5 & P5 & P5 \\
\hline November & P6 & P6 & P6 & P6 & P6 & P6 & P6 & P6 & P4 & $\mathrm{P} 4$ & P4 & P4 & P4 & P4 & P4 & P4 & P3 & P3 & P3 & P3 & P3 & P3 & P4 & P4 \\
\hline December & P6 & P6 & P6 & P6 & P6 & P6 & P6 & P6 & P2 & P2 & P1 & P1 & P1 & P2 & P2 & P2 & P2 & P2 & P1 & P1 & P1 & P2 & P2 & P2 \\
\hline
\end{tabular}

\begin{tabular}{|l|l|}
\hline P1 & 34 hours a year \\
\hline P2 & 46 hours a year \\
\hline P3 & 24 hours a year \\
\hline P4 & 40 hours a year \\
\hline P5 & 48 hours a year \\
\hline P6 & 120 hours a year \\
\hline
\end{tabular}

$\left(^{*}\right)$ Saturdays, Sundays and national holidays, P5 at all hours. Except substitutable and unscheduled holidays

(

Fig. 5 Energy calendars in Iberian Peninsula. Distribution of time periods for electricity tariffs. (UCS ENERGÍA. http://ucsenergia.com/calendariosenergeticos/-RD. 11/64 2001)

- $\mathrm{CE}_{F X} P(Y)$. Hourly electricity consumption in stage $X$ during $Y$ period. It will be measured in kw.

- $\mathrm{H}_{F X} P(Y)$. Working hours in stage $X$ during period $Y$. It will be measured in $\mathrm{h}$.

Being $X=1, \ldots, 9$ and $Y=1, \ldots, 6$.

Electricity consumption functions would be:

1.1. Extraction of raw materials/crushing It includes electricity consumption from the extraction of raw materials from the quarry to the entrance to the pre-homogenisation park (Stage 1: F1).

In the case of FYM HeidelbergCement Group factory in Malaga, there are two crushers. The function would be:

$$
\begin{aligned}
& \mathrm{CE} F(1)_{(t 1, t 2)}=\mathrm{CE}_{F 1} \quad P(1)_{(t 1)} * H_{F 1} P(1)_{(t 1)}+ \\
& \mathrm{CE}_{F 1} P(1)_{(t 2)} * H_{F 1} P(1)_{(t 2)}+\mathrm{CE}_{F 1} P(2)_{(t 1)} * H_{F 1} P(2)_{(t 1)}+ \\
& C E_{F 1} P(2)_{(\mathrm{t} 2)} * H_{F 1} P(2)_{(t 2)}+\mathrm{CE}_{F 1} P(3)_{(t 1)} * H_{F 1} P(3)_{(t 1)}+ \\
& \mathrm{CE}_{F 1} P(3)_{(t 2)} * H_{F 1} P(3)_{(\mathrm{t} 2)}+\mathrm{CE}_{F 1} P(4)_{(t 1)} * \mathrm{H}_{F 1} P(4)_{(t 1)}+ \\
& \mathrm{CE}_{F 1} P(4)_{(t 2)} * \mathrm{H}_{F 1} P(4)_{(t 2)}+\mathrm{CE}_{F 1} P(5)_{(t 1)} * \mathrm{H}_{F 1} P(5)_{(t 1)}+ \\
& \mathrm{CE}_{F 1} P(5)_{(t 2)}^{*} \mathrm{H}_{F 1} P(5)_{(t 2)}+\mathrm{CE}_{F 1} P(6)_{(t 1)} * H_{F 1} P(6)_{(t 1)}+ \\
& \mathrm{CE}_{F 1} P(6)_{(t 2)} * H_{F 1} P(6)_{(t 2)} .
\end{aligned}
$$

1.2. Homogenisation It includes transportation to the raw mill on crushing belts (Stage 2: F2).

- $\mathrm{CE}(F 2)=\mathrm{CE}_{F 2} P(1) * H_{F 2} P(1)+\mathrm{CE}_{F 2} P(2) * H_{F 2} P(2)$ $+\mathrm{CE}_{F 2} P(3) * H_{F 2} \mathrm{P}(3)+\mathrm{CE}_{F 2} P(4) * \mathrm{H}_{F 2} P(4)+$ $\mathrm{CE}_{F 2} P(5) * H_{F 2} P(5)+\mathrm{CE}_{F 2} P(6) * H_{F 2} P(6)$. 
1.3. Raw mill Electricity consumption of the mill and transportation of the elevators to the cyclone tower entrance (Stage: F3).

- $\mathrm{CE}(F 3)=\mathrm{CE}_{F 3} P(1) * H_{F 3} P(1)+\mathrm{CE}_{F 3} P(2) * H_{F 3} P(2)$ $+\mathrm{CE}_{F 3} P(3) * H_{F 3} P(3)+\mathrm{CE}_{F 3} P(4) * H_{F 3} P(4)+$ $\mathrm{CE}_{F 3} P(5) * H_{F 3} P(5)+\mathrm{CE}_{F 3} P(6) * H_{F 3} P(6)$

1.4. Clinker manufacturing Cyclones electricity consumption, clinker kiln, cooling fans, etc. (Stage 4: F4).

- $\mathrm{CE}(F 4)=\mathrm{CE}_{F 4} P(1) * H_{F 4} P(1)+\mathrm{CE}_{F 4} P(2) * H_{F 4} P(2)$ $+\mathrm{CE}_{F 4} P(3) * H_{F 4} P(3)+\mathrm{CE}_{F 4} P(4) * H_{F 4} P(4)+$ $\mathrm{CE}_{F 4} P(5) * H_{F 4} P(5)+\mathrm{CE}_{F 4} P(6) * H_{F 4} P(6)$

\subsection{Coal grinding (Stage 5: F5).}

- $\mathrm{CE}(F 4)=\mathrm{CE}_{F 5} P(1) * \mathrm{H}_{F 5} P(1)+\mathrm{CE}_{55} P(2) * H_{F 5} P(2)$ $+\mathrm{CE}_{F 5} P(3) * H_{F 5} P(3)+\mathrm{CE}_{F 5} P(4) * H_{F 5} P(4)+$ $\mathrm{CE}_{F 5} P(5) * H_{F 5} P(5)+\mathrm{CE}_{F 5} P(6) * H_{F 5} P(6)$.

\subsection{Cement mill (Stage 6: F6).}

In FYM HeidelbergCement Group factory in Malaga, there are three cement mills: (5, 6 and 7). The function would be:

- $\mathrm{CE}(F 6)_{(M 5, M 6, M 7)}=\mathrm{CE}_{F 6} P(1)_{(M 5)} * H_{F 6} P(1)_{(M 5)}+$ $\mathrm{CE}_{F 6} P(1)_{(M 6)}{ }^{*} H_{F 6} P(1)_{(M 6)}+\mathrm{CE}_{F 6} P(1)_{(M 7)}$

${ }^{*} H_{F 6} P(1)_{(M 7)}+\mathrm{CE}_{F 6} P(2)_{(M 5)} * H_{F 6} P(2)_{(M 5)}+$ $\mathrm{CE}_{F 6} P(2)_{(M 6)} * H_{F 6} P(2)_{(M 6)}+\mathrm{CE}_{F 6} P(2)_{(M 7)}$

${ }^{*} H_{F 6} P(2)_{(M 7)}+\mathrm{CE}_{F 6} P(3)_{(M 5)} * H_{F 5} P(3)_{(M 5)}+$

$\mathrm{CE}_{F 6} P(3)_{(M 6)} * H_{F 5} P(3)_{(M 6)}+\mathrm{CE}_{F 6} P(3)_{(M 7)}$

${ }^{*} H_{F 5} P(3)_{(M 7)}+\mathrm{CE}_{F 6} P(4)_{(M 5)} * H_{F 6} P(4)_{(M 5)}+$

$\mathrm{CE}_{F 6} P(4)_{(M 6)}{ }^{*} H_{F 6} P(4)_{(M 6)}+\mathrm{CE}_{F 6} P(4)_{(M 7)}$

${ }^{*} H_{F 6} P(4)_{(M 7)}+\mathrm{CE}_{F 6} P(5)_{(M 5)} * H_{F 6} P(5)_{(M 5)}+$

$\mathrm{CE}_{F 6} P(5)_{(M 6)}{ }^{*} H_{F 6} P(5)_{(M 6)}+\mathrm{CE}_{F 6} P(5)_{(M 7)}$

${ }^{*} H_{F 6} P(5)_{(M 7)}+\mathrm{CE}_{F 6} P(6)_{(M 5)} * H_{F 6} P(6)_{(M 5)}$

$\mathrm{CE}_{F 6} P(6)_{(M 6)} * H_{F 6} P(6)_{(M 6)}+\mathrm{CE}_{F 6} P(6)_{(M 7)}$

${ }^{*} \mathrm{H}_{\mathrm{F} 6} \mathrm{P}(6)_{(\mathrm{M} 7)}$

\subsection{Transportation (Stage 7: F7).}

- $\mathrm{CE}(F 7)=\mathrm{CE}_{F 7} P(1) * H_{F 7} P(1)+\mathrm{CE}_{F 7} P(2) * H_{F 7} P(2)$ $+\mathrm{CE}_{F 7} P(3) * H_{F 7} P(3)+\mathrm{CE}_{F 7} P(4) * H_{F 7} P(4)+$ $\mathrm{CE}_{F 7} P(5) * H_{F 7} P(5)+\mathrm{CE}_{F 7} P(6) * H_{F 7} P(6)$

1.8. Packaging (Stage 8: F8).

- $\mathrm{CE}(F 8)=\mathrm{CE}_{F 8} P(1) * H_{F 8} P(1)+\mathrm{CE}_{F 8} P(2) * H_{F 8} P(2)$ $+\mathrm{CE}_{F 8} P(3) * H_{F 8} P(3)+\mathrm{CE}_{F 8} P(4) * H_{F 8} P(4)+$ $\mathrm{CE}_{F 8} P(5) * H_{F 8} P(5)+\mathrm{CE}_{F 8} P(6) * H_{F 8} P(6)$.
Table 3 Powers contracted by Malaga factory (own elaboration)

\begin{tabular}{ll}
\hline & $\mathrm{Mw}$ \\
\hline MAXIMUM POWER_TWO TRANFORMERS & $20+20$ \\
CONTRACTED POWER IN P1 & 14 \\
CONTRACTED POWER IN P2 & 14 \\
CONTRACTED POWER IN P3 & 17.2 \\
CONTRACTED POWER IN P4 & 17.2 \\
CONTRACTED POWER IN P5 & 17.2 \\
CONTRACTED POWER IN P6 & 17.4 \\
\hline
\end{tabular}

1.9. Auxiliary services Offices and other services that are not directly related to production (Stage 9: F9).

$-\mathrm{CE}(F 9)=\mathrm{CE}_{F 9} P(1) * H_{F 9} \mathrm{P}(1)+\mathrm{CE}_{F 9} P(2)^{*} H_{F 9} P(2)$
$+\mathrm{CE}_{F 9} P(3)^{*} \mathrm{H}_{F 9} P(3)+\mathrm{CE}_{F 9} P(4)^{*} H_{F 7} P(4)+$
$\mathrm{CE}_{F 9} P(5)^{*} H_{F 9} P(5)+\mathrm{CE}_{F 9} P(6)^{*} H_{F 9} P(6)$

Genetic algorithms will be used to optimise-reduce-electricity consumption in each of the 9 stages of the process. Since $\mathrm{CE}_{\mathrm{FX}} P(Y)$ are fixed terms of the functions, genetic algorithms will operate on the variable terms $H_{\mathrm{FX}} P(Y)$. These algorithms continuously apply mechanisms for the selection, recombination and mutation of chromosomes. In our case, the mechanisms will consist of recombining $H_{\mathrm{FX}} P(Y)$, so that they are always used in descending order $(P 6, P 5, \ldots, P 1)$; that is, operating hours of the equipment in $P(6)$ will be first used, then those in $P(5), P(4),(\ldots)$, and finally the operating hours of the equipment in $P(1)$ will be used. This evolutive recombination cycle of the equation will continue until a stop or convergence criterion is met [32]. In our case, the criterion will be a certain $\%$ of reduction in electricity consumption.

STEP B2 On the one hand, in order to avoid exceeding access rate, six functions which limit this possibility were defined. Machinery power demand $(\mathrm{Mw})$ for each of the periods should never exceed the contracted power for that period.

On the other hand, by formulating other 6 algorithmic functions, the model will attempt to reduce the factory contracted power for each of the periods. Hence, if consumption for a period $\mathrm{P}_{\mathrm{i}}$ was lower than an established \% of the maximum contracted and was set in $\mathrm{C}^{\prime}$, less power could be contracted to lower the cost of the access rate in that period.

A total of 12 functions would be applied.

The powers contracted by Malaga factory are as follows (Table 3).

To develop the functions related to access rates, the following nomenclature will be used:

$\mathrm{CE}\left(P_{Y}\right)$ : energy consumption in $Y$ period. $Y=1,2, \ldots, 6$.

Electricity consumption in each period will be the sum of the consumptions registered for each of the stages in which 
we divided the cement manufacturing process. The maximum power limit for each established period can never be exceeded.

Consumption in stage 1 must take into consideration that two crushers are being used. In stage 6 , three cement mills will be operating: 5,6 and 7 .

B2.1. Functions to limit energy consumption in $P 1$ :

- $\mathrm{CE}\left(P_{1}\right)=\mathrm{CE}_{F 1} P(1)+\mathrm{CE}_{F 2} P(1)+\mathrm{CE}_{F 3} P(1)+\mathrm{CE}_{F 4} P(1)$ $+\mathrm{CE}_{F 5} P(1)+\mathrm{CE}_{F 6} P(1)+\mathrm{CE}_{F 7} P(1)+\mathrm{CE}_{F 8} P(1)+$ $\mathrm{CE}_{F 9} P(1) \leq 14 \mathrm{Mw}$

- If $0<=\mathrm{CE}(P 1) \leq C^{\prime} \mathrm{Mw}$ (1 month under normal conditions) $\rightarrow$ Access rate may be reduced.

\section{B2.2. Functions to limit energy consumption in $P 2$ :}

- $\mathrm{CE}\left(P_{2}\right)=\mathrm{CE}_{F 1} P(2)+\mathrm{CE}_{F 2} P(2)+\mathrm{CE}_{F 3} P(2)+\mathrm{CE}_{F 4} P(2)$ $+\mathrm{CE}_{F 5} P(2)+\mathrm{CE}_{F 6} P(2)+\mathrm{CE}_{F 7} P(2)+\mathrm{CE}_{F 8} P(2)+$ $\mathrm{CE}_{F 9} P(2) \leq 14 \mathrm{Mw}$.

- If $0<=\mathrm{CE}\left(P_{2}\right) \leq C^{\prime} \mathrm{Mw}$ (1 month under normal conditions) $\rightarrow$ Access rate may be reduced.

\section{B2.3. Functions to limit energy consumption in $P 3$ :}

- $\mathrm{CE}\left(P_{3}\right)=\mathrm{CE}_{F 1} P(3)+\mathrm{CE}_{F 2} P(3)+\mathrm{CE}_{F 3} P(3)+\mathrm{CE}_{F 4} P(3)$ $+\mathrm{CE}_{F 5} P(3)+\mathrm{CE}_{F 6} P(3)+\mathrm{CE}_{F 7} P(3)+\mathrm{CE}_{F 8} P(3)+$ $\mathrm{CE}_{F 9} P(3) \leq 17.2 \mathrm{Mw}$.

- If $0 \leq \mathrm{CE}\left(P_{3}\right) \leq C^{\prime} \quad(1$ month under normal conditions) $\rightarrow$ Access rate may be reduced.

B2.4. Functions to limit energy consumption in P4:

- $\mathrm{CE}\left(P_{4}\right)=\mathrm{CE}_{F 1} P(4)+\mathrm{CE}_{F 2} P(4)+\mathrm{CE}_{F 3} P(4)+\mathrm{CE}_{F 4} P(4)$ $+\mathrm{CE}_{F 5} P(4)+\mathrm{CE}_{F 6} P(4)+\mathrm{CE}_{F 7} P(4)+\mathrm{CE}_{F 8} P(4)+$ $\mathrm{CE}_{F 9} P(4) \leq 17.2 \mathrm{Mw}$

- If $0 \leq \mathrm{CE}\left(P_{4}\right) \leq C^{\prime} \quad(1$ month under normal conditions) $\rightarrow$ Access rate may be reduced.

B2.5. Functions to limit energy consumption in P5:

- $\mathrm{CE}\left(P_{5}\right)=\mathrm{CE}_{F 1} P(5)+\mathrm{CE}_{F 2} P(5)+\mathrm{CE}_{F 3} P(5)+\mathrm{CE}_{F 4} P(5)$ $+\mathrm{CE}_{F 5} P(5)+\mathrm{CE}_{F 6} P(5)+\mathrm{CE}_{F 7} P(5) \mathrm{CE}_{F 8} P(5)+$ $\mathrm{CE}_{F 9} P(5) \leq 17.2 \mathrm{Mw}$.

- If $0 \leq \mathrm{CE}\left(P_{5}\right) \leq C^{\prime} \quad(1$ month under normal conditions $) \rightarrow$ Access rate may be reduced.

B2.6. Functions to limit energy consumption in P6:

- $\mathrm{CE}\left(P_{6}\right)=\mathrm{CE}_{F 1} P(6)+\mathrm{CE}_{F 2} P(6)+\mathrm{CE}_{F 3} P(6)+\mathrm{CE}_{F 4} P(6)$ $+\mathrm{CE}_{F 5} P(6)+\mathrm{CE}_{F 6} P(6)+\mathrm{CE}_{F 7} P(6)+\mathrm{CE}_{F 8} P(6)+$ $\mathrm{CE}_{F 9} P(6) \leq 17.4 \mathrm{Mw}$
- If $0 \leq \mathrm{CE}\left(P_{5}\right) \leq C^{\prime} \quad(1$ month under normal conditions $) \rightarrow$ Access rate may be reduced.

B2.7. Limiting power by extension rights: the contracted power must be $<20 \mathrm{Mw}$ :

The factory in our case has two parallel redundant $20 \mathrm{Mw}$ transformers. The energy consumption functions of the different periods should not exceed the $20 \mathrm{Mw}$ limit.

STEP B3: "operation and sales restrictions" functions

The model will use another 9 functions that will be called "Operation and Sales Restriction Functions". They will represent the following:

- The maximum production capacity of each stage of the cement manufacturing process minus the maximum capacity of next stage should be $>0$, and at the same time $\leq$ than the storage capacity of raw material, fuel, by-product or final product at each stage of the process ( 7 functions).

- Time constraints (2 functions).

For these new functions, we will take into consideration the following nomenclature and data measured in tons/hour $(\mathrm{t} / \mathrm{h})$ (Malaga factory):

- $\mathrm{CP}_{F 1(t 1)}$ : maximum production capacity per hour, in the extraction of raw materials stage. $300 \mathrm{t} / \mathrm{h}$.

- $\mathrm{CP}_{F 1(t 2)}$ : maximum production capacity per hour, in the extraction of raw materials stage. $520 \mathrm{t} / \mathrm{h}$.

- CAMp: maximum storage capacity for crushed raw materials.

- $\mathrm{CP}_{\mathrm{F} 2}$ : maximum production capacity per hour in the homogenisation stage. $320 \mathrm{t} / \mathrm{h}$.

- CAMpH: maximum homogenised raw material capacity.

- $\mathrm{CP}_{\mathrm{F} 3}$ : maximum production capacity per hour in the crude grinding stage. $550 \mathrm{t} / \mathrm{h}$.

- CACr: maximum crude oil storage capacity.

- $\mathrm{CP}_{\mathrm{F} 4}$ : maximum production capacity per hour in clinker manufacturing process/kiln. For raw materials: $240 \mathrm{t} / \mathrm{h}$. For clinker: $154 \mathrm{t} / \mathrm{h}$

- CACk: maximum clinker storage capacity.

- $\mathrm{CP}_{\mathrm{F} 5}$ : maximum production capacity per hour in the coal grinding stage. $17.1 \mathrm{t} / \mathrm{h}$.

- CACb: maximum coal storage capacity.

- $\mathrm{CP}_{\mathrm{F} 6}$ : maximum production capacity per hour in the cement grinding stage:

- $\mathrm{CP}_{F 6(M 5)}$-Cement mill 5: $29.2 \mathrm{t} / \mathrm{h}$.

- $\mathrm{CP}_{F 6(M 6)}$-Cement mill 6: $78 \mathrm{t} / \mathrm{h}$.

- $\mathrm{CP}_{F 6(M 7)}$-cement mill 7: $34.3 \mathrm{t} / \mathrm{h}$.

- $\mathrm{CP}_{\mathrm{F} 7}$ : maximum production capacity per hour in the transportation stage. 
- CASL_CEM(Z): maximum cement storage capacity in silo $Z$.

- $\mathrm{CP}_{\mathrm{F} 8}$ : maximum production capacity per hour in the packing stage.

There are two packing lines with the following capacities:

- Line 1: $67 \mathrm{t} / \mathrm{h}(2700$ sacks).

- Line 2: 55 t/h (2200 sacks).

- CAEns: maximum storage capacity in sacks storehouse.

- $\mathrm{CP}_{F 9}$ : maximum production capacity per hour in the auxiliary services stage.

- $\mathrm{VE}_{\mathrm{CEM}(Z)}$ : SALES of packaged cement type $Z$, being $Z=$ $1, \ldots, n$.

- $\mathrm{VG}_{\mathrm{CEM}(Z)}$ : sales of bulk cement type $Z$, being $Z=1, \ldots$, $n$.

- CC: consumption of coal, measured in $\mathrm{t} / \mathrm{h}$.

1. Crusher maximum capacity. Stage 1 Extraction of raw materials.

- $\mathrm{CAMp} \geq \mathrm{CP}_{F 1(t 1)} *\left[H_{F 1} P(1)_{(t 1)}+H_{F 1} P(2)_{(t 1)}+\right.$ $\left.H_{F 1} P(3)_{(t 1)}+H_{F 1} P(4)_{(t 1)}+H_{F 1} P(5)_{(t 1)}+H_{F 1} P(6)_{(t 1)}\right]$ $+\mathrm{CP}_{F 1(t 2)} *\left[H_{F 1} P(1)_{(t 2)}+H_{F 1} P(2)_{(t 2)}+H_{F 1} P(3)_{(t 2)}\right.$ $\left.+H_{F 1} P(4)_{(t 2)}+H_{F 1} P(5)_{(t 2)}+H_{F 1} P(6)_{(t 2)}\right]-$ $\mathrm{CP}_{F 2} *\left[H_{F 1} P(1)+H_{F 1} P(2)+H_{F 1} P(3)+H_{F 1} P(4)+\right.$ $\left.H_{F 1} P(5)+H_{F 1} P(6)\right] \geq 0$.

Time constraints function:

$H_{F 1} P(1)_{(t 1)}, \quad H_{F 1} P(2)_{(\mathrm{t} 1)}, \quad H_{F 1} P(3)_{(t 1)}, \quad H_{F 1} P(4)_{(t 1)}$, $H_{F 1} P(5)_{(t 1)}, \quad H_{F 1} P(6)_{(t 1)}, \quad H_{F 1} P(1)_{(t 2)}, \quad H_{F 1} P(2)_{(t 2)}$, $H_{F 1} P(3)_{(t 2)}, \quad H_{F 1} P(4)_{(t 2)}, \quad H_{F 1} P(5)_{(t 2)}, \quad H_{F 1} P(6)_{(t 2)} \in 7-$ 23 hours

2. Homogenisation stage maximum capacity.

- $\mathrm{CAMpH} \geq \mathrm{CP}_{F 2} *\left[H_{F 2} P(1)+H_{F 2} P(2)+H_{F 2} P(3)+\right.$ $\left.H_{F 2} P(4)+H_{F 2} P(5)+H_{F 2} P(6)\right]-\mathrm{CP}_{F 3} *\left[H_{F 3} P(1)\right.$ $+H_{F 3} P(2)+H_{F 3} P(3)+H_{F 3} P(4)+H_{F 3} P(5)+$ $\left.\left.H_{F 3} P(6)\right]\right) \geq 0$

No time constraints.

3. Raw material mill maximum capacity.

- $\mathrm{CACr} \geq \mathrm{CP}_{F 3} *\left[H_{F 3} P(1)+H_{F 3} P(2)+H_{F 3} P(3)+\right.$ $\left.H_{F 3} P(4)+H_{F 3} \mathrm{P}(5)+H_{F 3} \mathrm{P}(6)\right]-\mathrm{CP}_{F 4} *\left[H_{F 4} P(1)+\right.$ $\left.H_{F 4} P(2)+H_{F 4} P(3)+H_{F 4} P(4)+H_{F 4} P(5)+H_{F 4} P(6)\right] \geq 0$

No time constraints.

4. Clinker manufacturing maximum capacity (kiln).
- $\mathrm{CACk} \geq \mathrm{CP}_{F 4} *\left[H_{F 4} P(1)+H_{F 4} P(2)+H_{F 4} P(3)+\right.$ $\left.H_{F 4} P(4)+H_{F 4} P(5)+H_{F 4} P(6)\right]-\mathrm{CP}_{F 6} *\left[H_{F 6} P(1)+\right.$ $H_{F 6} P(2)+H_{F 6} P(3)+H_{F 6} P(4)+H_{F 6} P(5)+H_{F 6} P(6) \geq 0$

No time constraints.

5. Coal mill maximum capacity.

- $\mathrm{CACb} \geq \mathrm{CP}_{F 5} *\left[H_{F 5} P(1)+H_{F 5} P(2)+H_{F 5} P(3)+\right.$ $\left.H_{F 5} P(4)+H_{F 5} P(5)+H_{F 5} P(6)\right]-\mathrm{CC}^{*}\left[H_{F 6} P(1)+\right.$ $\left.H_{F 6} P(2)+H_{F 6} P(3)+H_{F 6} P(4)+H_{F 6} P(5)+H_{F 6} P(6)\right] \geq 0$

No time constraints.

6. Cement mill maximum capacity/maximum capacity for transportation.

We will have one function for each of the $Z$ types of cement that is manufactured in the factory, being $Z=1,2, \ldots, n$.

- CASL_CEM $(Z) \geq \mathrm{CP}_{F 6(M 5)} *\left[H_{F 6} P(1)_{(M 5)}+\right.$ $H_{F 6} P(2)_{(M 5)}+H_{F 6} P(3)_{(M 5)}+H_{F 6} P(4)_{(M 5)}+$ $\left.H_{F 6} P(5)_{(M 5)}+H_{F 6} P(6)_{(M 5)}\right]+\mathrm{CP}_{F 6(M 6)} *\left[H_{F 6} P(1)_{(M 6)}\right.$ $+H_{F 6} P(2)_{(M 6)}+H_{F 6} P(3)_{(M 6)}+H_{F 6} P(4)_{(M 6)}+$ $\left.H_{F 6} P(5)_{(M 6)}+H_{F 6} P(6)_{(M 6)}\right]+\mathrm{CP}_{F 6(M 7)} *\left[H_{F 6} P(1)_{(M 7)}\right.$ $+H_{F 6} P(2)_{(M 7)}+H_{F 6} P(3)_{(M 7)}+H_{F 6} P(4)_{(M 7)}+$ $\left.H_{F 6} P(5)_{(M 7)}+H_{F 6} P(6)_{(M 7)}\right]-\mathrm{CP}_{F 7}\left[H_{F 7} P(1)+\right.$ $\left.H_{F 7} P(2)+H_{F 7} P(3)+H_{F 7} P(4)+H_{F 7} P(5)+H_{F 7} P(6)\right]$ $-\mathrm{CP}_{F 8} *\left[H_{F 8} P(1)+H_{F 8} P(2)+H_{F 2} P(3)+H_{F 8} P(4)+\right.$ $\left.H_{F 8} P(5)+H_{F 8} P(6)\right]-\mathrm{VG}_{\mathrm{CEM}(Z)} \geq 0$

No time constraints.

7. Packing maximum capacity.

We will have a function for each of the $Z$ types of cement that is manufactured in the factory, being $Z=1,2, \ldots, n$.

- CAEns $\geq \mathrm{CP}_{F 8} *\left[\mathrm{H}_{F 8} P(1)+\mathrm{H}_{F 8} P(2)+H_{F 2} P(3)+\right.$ $\left.H_{F 8} P(4)+H_{F 8} P(5)+H_{F 8} P(6)\right]-\operatorname{VE}_{\mathrm{CEM}}(Z) \geq 0$.

$\mathrm{VE}_{\mathrm{CEM}(Z)}$ : sales of already packed type $Z$ cement, being $Z=1, \ldots, n$.

Time constraints function:

$H_{F 8} P(1), \quad H_{F 8} P(2), \quad H_{F 8} P(3), \quad H_{F 8} P(4), \quad H_{F 8} P(5)$, $H_{F 8} P(6) \in 7-23 \mathrm{~h}$.

8. Auxiliary services maximum capacity.

In this stage, there would be no such constraints.

Taking into consideration the demand for clinker and different types of cement, electricity consumption functions, restrictions on access rates and on available transformers, as well as operating and selling restrictions, the use of genetic algorithms will make the system suggest us the changes we should make to move production to lower cost periods ( $P 6$, $P 5, P 4$, etc.). 
Genetic algorithms continuously apply mechanisms of selection, recombination and mutation of chromosomes, which in our case would be the different regulated prices, until an optimal value is reached.

\section{Results: innovation brought by the model}

First of all, the research major novelty is that the model that evolved was an absolutely innovative model, since it was developed by applying a series of basic algorithms which were based on AI techniques, though expressly addressed to the cement sector.

Thanks to the experts contributions and the studied bibliography, it was possible to include the variables that condition not only electricity consumption, but also the knowledge of machinery behaviour and operational processes in cement plants.

Secondly, the global research developed resulted in a model that integrates three complementary aspects, which enables a higher level of electricity cost optimisation than that obtained in previous researches, which focussed on one of the aspects in isolation. This question implies an innovation in the research, as well as in the resulting model.

The three aspects on which the model for electricity cost optimisation was focussed are described below. Only the first two are the object of this paper.

(1) Process variables which incur zero or very low costs [36].

(2) Regulated electricity costs. Machinery running is shifted to the most economical off-peak times [37].

(3) Price of electricity in the market $[16,28,39,40]$.

Thirdly, due to the scarce previous literature, a panel of experts was held, which provided qualitative and quantitative information to approach the issue from a realistic, updated and complete business viewpoint. The experts enabled the gathering of information on all Spanish cement factories.

The use of the expert panel represents an innovative element in researches in this field, since none of them had previously made use of consultations with experts.

The panel of experts provided better results for the model, since their expertise made it possible to select more and better process variables to optimise the cost of electricity. Moreover, the experts were extremely useful when selecting the most appropriate AI tools.

Fourthly, quantitative data obtained from expert surveys provided another of the main results of the research. It is a quite utterly novel quantitative study about the composition of regulated electricity cost in Spanish cement industry. The study was of great use for the optimisation of regulated electricity costs in our research. It will also provide the basis for other future researches about electrical aspects in Spanish cement sector.

Fifthly, we would like to remark that the model obtained for the optimisation of electricity cost can be applied to any of the cement factories that are distributed throughout the world, since the production process is the same as that followed by the factory considered. If it was chosen to be applied in other countries, only the composition of regulated electricity costs should be considered, along with the different factors that could affect electricity price formation in the market.

Furthermore, by introducing certain modifications to the initial parameters, the model could be applied to other electro-intensive processing industries.

Consequently, we would like to highlight that the results obtained can serve as a basis for future researches, since the model is perfectly able to be reproduced for other industrial sectors. Therefore, a remarkably interesting line of research for other sectors or even for intersectoral comparison is opened.

\section{Conclusions}

1. It is possible to optimise electricity cost in cement factories by means of influencing certain process variables and incurring zero or very low costs, as it is shown in $[36,37]$. Through ANN we will obtain the optimal combination of these variables, which minimises electricity consumption in the production process.

2. We can reduce electricity cost by optimising regulated electricity prices, that is, by shifting the use of that machinery with a higher electricity consumption in the factory to periods with lower regulated electricity costs $[36,37]$. By means of using genetic algorithms we will optimise the costs of regulated electricity prices.

3. The model resulting from this research process may be applied to any cement factory in the world. By modifying initial parameters, it could be applied to other electrointensive processing industries. It is therefore a model that offers great versatility.

4. This model enhances products development-cement and other industrial products. The methodology brought forth contributes to influence and transform the way we live and work, since it makes industries more competitive. Competitiveness helps companies generate more activity, added value and employment [2, 3].

5. Owing to its complexity, this article has its limitation, since it only addresses a part of a broader research process which integrates three different approaches to the optimisation of electricity cost in cement factories. In particular, the present paper approaches certain variables in the cement manufacturing production process and the optimisation of regulated electricity costs. 
Author's contribution Conceptualisation: The four authors worked in the ideas and evolution of the article. Methodology: All authors contributed to the development of the methodology during the whole process. Software: No software was used in this article. Validation: The reproducibility of results was carried out by Manuel Parejo, Pedro Mora and Benito Navarrete. Formal Analysis: Statistical and mathematical techniques to analyse and synthesise study data were applied by Manuel Parejo and Pedro Mora. Investigation: All authors worked in the research and investigation process, and data collection. Resources: The four authors provided study materials and analysis tools. Data Curation: The four authors participated in this matter. Writing original draft: Manuel Parejo wrote the original draft with the help of the other three authors. Writing-Reviews and Editing: The four authors reviewed the original article and worked in the definitive article. Visualisation: The four authors contributed to the presentation of the published work. Supervision: The four authors worked in this matter. Project Administration: All authors contributed to the coordination of the research activity planning. Funding Acquisition: There was no financial support for this project.

Funding Open Access funding provided thanks to the CRUE-CSIC agreement with Springer Nature. The authors declare that they have no known competing financial interests or personal relationships that could have appeared to influence the work reported in this paper.

\section{Declarations}

Conflict of interest We have no conflicts of interest to disclose, but we do respectfully request that Dr. Salmerón.

Open Access This article is licensed under a Creative Commons Attribution 4.0 International License, which permits use, sharing, adaptation, distribution and reproduction in any medium or format, as long as you give appropriate credit to the original author(s) and the source, provide a link to the Creative Commons licence, and indicate if changes were made. The images or other third party material in this article are included in the article's Creative Commons licence, unless indicated otherwise in a credit line to the material. If material is not included in the article's Creative Commons licence and your intended use is not permitted by statutory regulation or exceeds the permitted use, you will need to obtain permission directly from the copyright holder. To view a copy of this licence, visit http://creativecomm ons.org/licenses/by/4.0/.

\section{References}

1. Alfalla-Luque R, Medina-Lopez CA, Dey PK (2013) Supply chain integration framework using literature review. Prod Plan Control: Manag Oper 24(8-9):800-817. https://doi.org/10.1080/09537287. 2012.666870

2. Andrew N (2017) Artificial intelligence is the new electricity. Newstex Global Business Blogs

3. Andrew NG, Zhang T (2017) The optimistic promise of artificial intelligence; how AI is going to be like electricity, transforming every industry. Wall Street J (online). (ISSN: 2574 9579)

4. Azadeh A, Sohrabi P, Saberi M (2015). A unique meta-heuristic algorithm for optimization of electricity consumption in energyintensive industries with stochastic inputs. International Journal of Advanced Manufacturing Technology. June, 2015. (ISSN: 1443-3015).
5. Barbosa M, Grayson D (2009) Site visits: assessing and improving the climate for women in physics. In Harline BK, Horton KR, Kaicher CM (eds) AIP conference proceedings. American Institute of Physics. https://doi.org/10.1063/1.3137748

6. Barlow M (2015) Learning to love data science. Exploring Predictive Analytics, Machine Learning, Digital Manufacturing and Supply Chain Optimisation. United States of America

7. Bramer M (2007) Principles of data mining. Springer, London (2007)

8. Chaoqum M, Guojun G, Jianhong W (2007) Data clustering theory, algorithms and applications. United States of America

9. Castañón AM, García-Granda S, Guerrero A, Lorenzo MP, Angulo S (2014) Energy and environmental savings via optimisation of the production process at a Spanish cement Factory. J Clean Prod Elsevier (ISSN: 0959-6526)

10. Cronin P, Ryan F, Coughlan M (2008) Undertaking a literature review: a step-by-step approach. Br J Nurs 17(1):38-43

11. Eurostat (2019) Estadísticas de precios eléctricos.https://appsso.Eurostat.ec.€pa.eu/nui/submitViewTableAction.do

12. Fabbe-Costes N, Jahre M, Roussat C (2009) Supply chain integration: the role of logistics service providers. Int J Prod Perform Manag 58(1):71-91

13. Gilvonio LR, Inche-Mitma JL (2005) El Ahorro de energía en la industria cementera como estrategia de la excelencia operativa (tesis doctoral). Universidad Mayor de San Marcos, Lima

14. Hemingway P, Brereton N (2009) What is a systematic review? Series, 2nd edn. Hayward Medical Communications, Newmarket

15. Hernández J, Ramírez MJ, Ferri C (2004) Introducción a la minería de datos. Pearson Educación, Madrid

16. Hurtado, L., Quintero, O.L. \& García, J. J., (2014). Estimación del precio de oferta de la energía eléctrica en Colombia mediante inteligencia artificial. Rev Mét Cuant Para Econ Empresa. ISSN: 1886-516X

17. Khotanzad AI (2018) Using artificial intelligence to develop electricity load forecasts. Power Magazine 62(6): 1

18. Lane J, Wade J, Down L, Bonnington S, Holding P, Lennon T (2011) A peer review intervention for monitoring and evaluating sites (PRIME) that improved randomized controlled trial conduct and performance. J Clin Epidemiol 64(6):628-636

19. Lara J (2014) Minería de datos. Centro de Estudios Financieros, Madrid

20. Michalewicz Z (1999) Genetic algorithms + data structures $=$ evolution programs. Ed. Springer

21. Nagi J (2009) An intelligent system for detection of non-technical losses in Tenaga Nasional Berhad (TNB) Malaysia low voltage distribution network. University Tenaga Nasional, Malasia

22. Nagi J, Yap KS, Tiong SK, Ahmed SK, Mohamad M (2010) Nontechnical loss detection for metered customers in power utility using support vector machines. IEEE Trans Power Deliv 25(2):1162-1171

23. Nagi J, Mohammad AM, Yap KS, Tiong SK, Ahmed SK (2008) Non-technical loss analysis for detection of electricity theft using support vector machines. IEEE International Conference on Power and Energy, pp 907-912

24. Nagi J, Yap KS, Nagi F, Koh SK, Ahmed SK (2010) NTL detection of electricity theft and abnormalities for large power consumers in TNB Malaysia. In: IEEE SCORED, pp 13-14

25. OAkley A (2003) Research evidence: knowledge management and educational practice: early lessons from a systematic approach. Lond Rev Educ 1(1):21-33

26. OFICEMEN (2019) Informes Estadísticos Avance Nacional Diciembre 2019. https://www.oficemen.com/shop/

27. Parejo M, Navarrete B, Mora P, Alfalla-Luque R (2021) Desarrollo metodológico para la optimización del coste eléctrico en fábricas de cemento, mediante inteligencia artificial, operando sobre el coste eléctrico del mercado. Dirección y Organización. Julio, 74, pp 5-19 
28. Pavlos SG (2007) Artificial intelligence solution to electricity price forecasting problem. Appl Arti Intell 21(8):707-727

29. Pereira L, Afonso L, Papa JP, Vale ZA, Ramos C, Gastaldello DS, Souza AN (2013) Multilayer perceptron neural networks training through charged system search and its application for non-technical losses detection. In: IEEE PES, ISGT Latin America

30. Pérez C (2007) Minería de datos técnicas y herramientas. Thomson, Madrid

31. Provost F, Fawcett T (2013) Data science for business. O'Reilly Median Inc., USA

32. Quinlan KM, Kane M, Trochim WMK (2008) Evaluation of large research initiatives: outcomes, challenges, and methodological considerations. In: (Series Ed.) \& Coryn CLS, Scriven M (eds) New directions for evaluation, No 118: Reforming the evaluation of research, pp 61-72

33. Ramos CC, de Sousa AN, Papa JP, Falcao AX (2011) A new approach for nontechnical losses based on optimum-path forest. IEEE Trans Power Syst 26(1):181-189

34. Sánchez Cazorla A, Alfalla-Luque R, Irimia-Diéguez AI (2016) Risk identification in megaprojects as a crucial stage of risk management: a literature review. Proj Manag J 47(6):75-93

35. Shaohog J, Wemeng XY, Xiaohong W (2012) Research on the key technology of energy management and optimization in cement enterprises. Adv Mater Res 433-440:1910-1914
36. Swanepoel JA (2013) Modeling for integrated energy optimization in cement production. In: Conference on the industrial and commercial use of energy, ICUE. Article number: 6761634. ISSN: 0196-8904

37. Swanepoel JA, Mathews EH, Vosloo J, Liebenberg L (2013) Integrated energy optimisation for the cement industry: a case study perspective. Energy Convers Manag 78:765-775. ISSN:0196-8904

38. Tranfield D, Denyer D, Smart P (2003) Towards a methodology for developing evidence-informed management knowledge by means of systematic review. Br J Manag 14(3):207-222

39. Wellesley M (2011) EnvaPower's new artificial intelligence software makes managing electricity a no-brainer. PR Newswire, New York

40. Zhang J, Cheng Ch (2008) Day-ahead electricity price forecasting using artificial intelligence. In: IEEE Canada electric power conference. INSPEC Accession Number: 10459652

Publisher's Note Springer Nature remains neutral with regard to jurisdictional claims in published maps and institutional affiliations. 